\title{
? RETO DIAGNÓSTICO: Hallazgos incidentales en la necropsia de un pájaro carpintero bellotero (Melanerpes formicivorus)
}

Edson Paul Juárez-Rojas* D 0000-0002-7821-8646 Fernando Chávez Maya (1) 0000-0002-4330-3410 Gary Garcia Espinosa D 0000-0001-9477-6130

Norma L. Calderón Apodaca (1) 0000-0001-9898-3823

"Coordinador Médico de Hospital Veterinario Rampu, CDMX Universidad Nacional Autónoma de México. Facultad de Medicina Veterinaria y Zootecnia. Departamento de Medicina y Zootecnia de Aves

* Autor para correspondencia: Correo electrónico: edzonpaul@gmail.com
Recibido: 2020-02-18 Aceptado: 2021-06-07 Publicado: 2021-08-23

Información y declaraciones adicionales en la página 15

(a) Derechos de autor: Edson Paul Juarez Rojas et al. 2021

acceso abierto $\boldsymbol{O}$

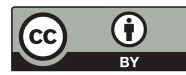

Distribuido bajo una Licencia Creative Commons Atribución 4.0 Internacional (CC-BY 4.0)

\section{Historia clínica}

El cadáver de un pájaro carpintero silvestre (Melanerpes formicivorus) fue remitido al Laboratorio de Diagnóstico e Investigación en Enfermedades de las Aves, de la FMVZ-UNAM en marzo de 2019 para determinar la causa de muerte a través de un estudio de necropsia e histopatología (Figura 1). La persona responsable de llevar el cadáver al laboratorio de diagnóstico informó que había visto previamente al ave en un nido junto a su pareja en un jardín urbano donde días antes se había rociado insecticida a las plantas.

En el laboratorio se realizó la técnica de necropsia con base en el protocolo de necropsia de aves ${ }^{1}$. Durante la inspección externa, se observaron hematomas en la articulación humero-clavicular y sobre los músculos intercostales superficiales de las costillas cinco a siete del lado derecho, además de un desgarre muscular y una fractura transversal media en la costilla seis, también del lado derecho.

En el tórax se observó un coágulo en la superficie del pulmón derecho, además ambos pulmones presentaron una marcada congestión. En el músculo esquelético occipital del cráneo se observaron varias estructuras alargadas, ovoides, de color blanco de aproximadamente $2^{2} 1 \mathrm{~mm}$ entre las fibras musculares, estas estructuras se asociaron con vacuolas parasitóforas (Figura 2).

Para el estudio histopatológico se tomaron muestras del músculo occipital del cráneo y el encéfalo, además de muestras de pulmón e hígado para orientar el diagnóstico debido a la poca información previa a la muerte del ave. Las muestras fueron fijadas en formol al $10 \%$ con un $\mathrm{pH}$ de 7.4 y procesadas rutinariamente. Posteriormente se realizaron cortes de entre cinco y diez micras, y fueron teñidas con hematoxilina y eosina (HE).

\section{Una forma de citar este artículo:}

Juárez Rojas EP, Chávez Maya F, García Espinosa G, Calderón Apodaca NL. Hallazgos incidentales en la necropsia de un pájaro carpintero bellotero (Melanerpes formicivorus). Clínica veterinaria: abordaje diagnóstico y terapéutico. 2021;7:e59202172. doi:10.22201/ fmvz.23958766e.2021.7.59 
En las fibras musculares y el cerebelo se observaron vacuolas alargadas y ovoides asociadas con parásitos apicomplexos (Figuras 3 y 4). En el encéfalo se observaron infiltrados perivasculares de linfocitos en grado moderado, así como hemorragias y espongiosis (Figuras 5 y 6). En el parénquima de pulmón se observó congestión difusa severa con zonas extensas de hemorragia (Figura 7), asociada a las múltiples lesiones traumáticas en la zona intercostal derecha. En el hígado se observó degeneración grasa de los hepatocitos con distribución difusa de grado severo (Figura 8).

Al hallarse las estructuras parasitarias y ser muy semejantes a los sarcoquistes del género Sarcocystis, se decidió realizar una identificación de la especie del agente etiológico sospechoso, se decidió identificar si las especies etiológicas correspondían a alguna con un alto índice de reportes en diferentes especies de hospederos ${ }^{2,3}$. Además, se identificaría y relacionaría si los sarcoquistes en músculo occipital correspondían a la misma especie de vacuola parasitofóra hallada en las lesiones del cerebelo y encéfalo.

Para realizar las pruebas moleculares, algunas de las secciones de tejido de músculo y encéfalo, que habían sido incluidas en parafina, fueron procesadas para ser desparafinadas, disecadas y suspendidas en una solución amortiguada, para la extracción de ADN. Se realizó prueba de PCR para detectar Sarcocystis neurona y S. falcatula ${ }^{3}$ (Figura 9).

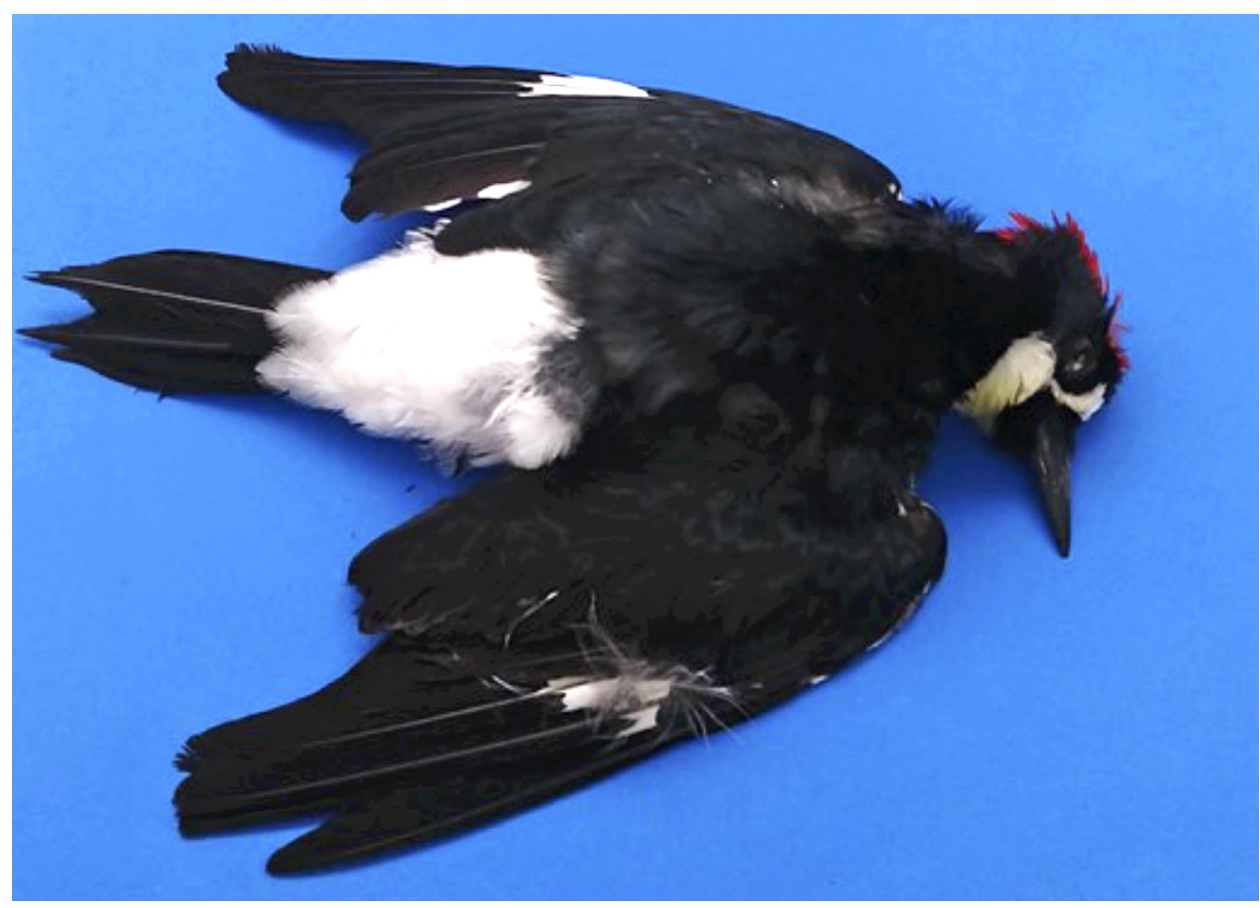

Figura 1. Cadáver del pájaro carpintero bellotero (Melanerpes formicivorus) antes de la necropsia. 


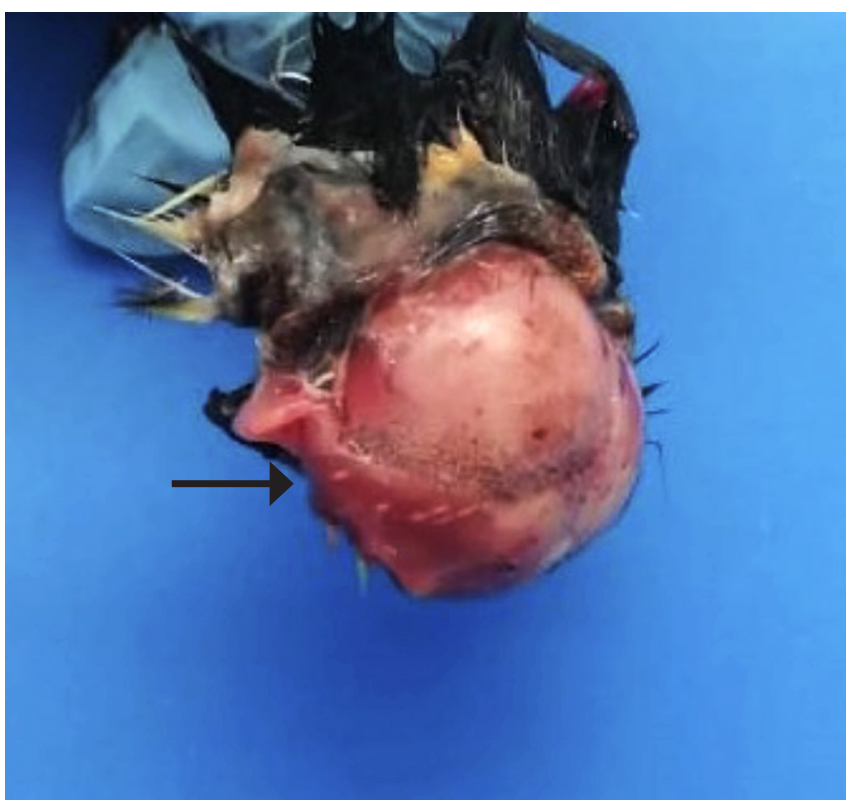

Figura 2. Músculo occipital izquierdo del pájaro carpintero bellotero (Melanerpes formicivorus). Se observan estructuras blancas, alargadas y ovoides en el músculo esquelético asociadas con sarcoquistes (flecha).

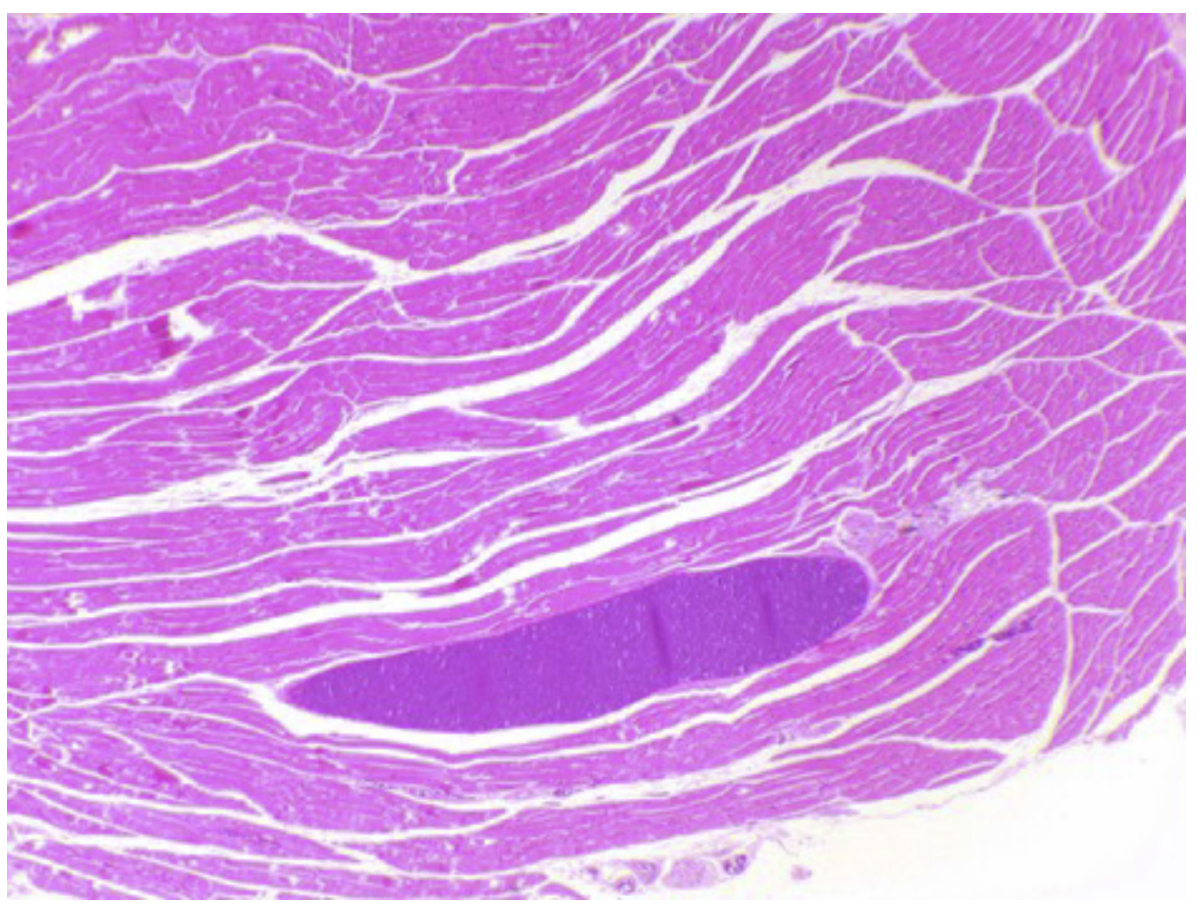

Figura 3. Sarcoquistes de Sarcocystis sp. en músculo esquelético occipital. En el músculo se observaron varias vacuolas parasitóforas de entre las fibras musculares y el tejido muscular sin reacciones inflamatorias, pero con degeneración y rabdomiólisis leves asociadas a Sarcocystis sp. 


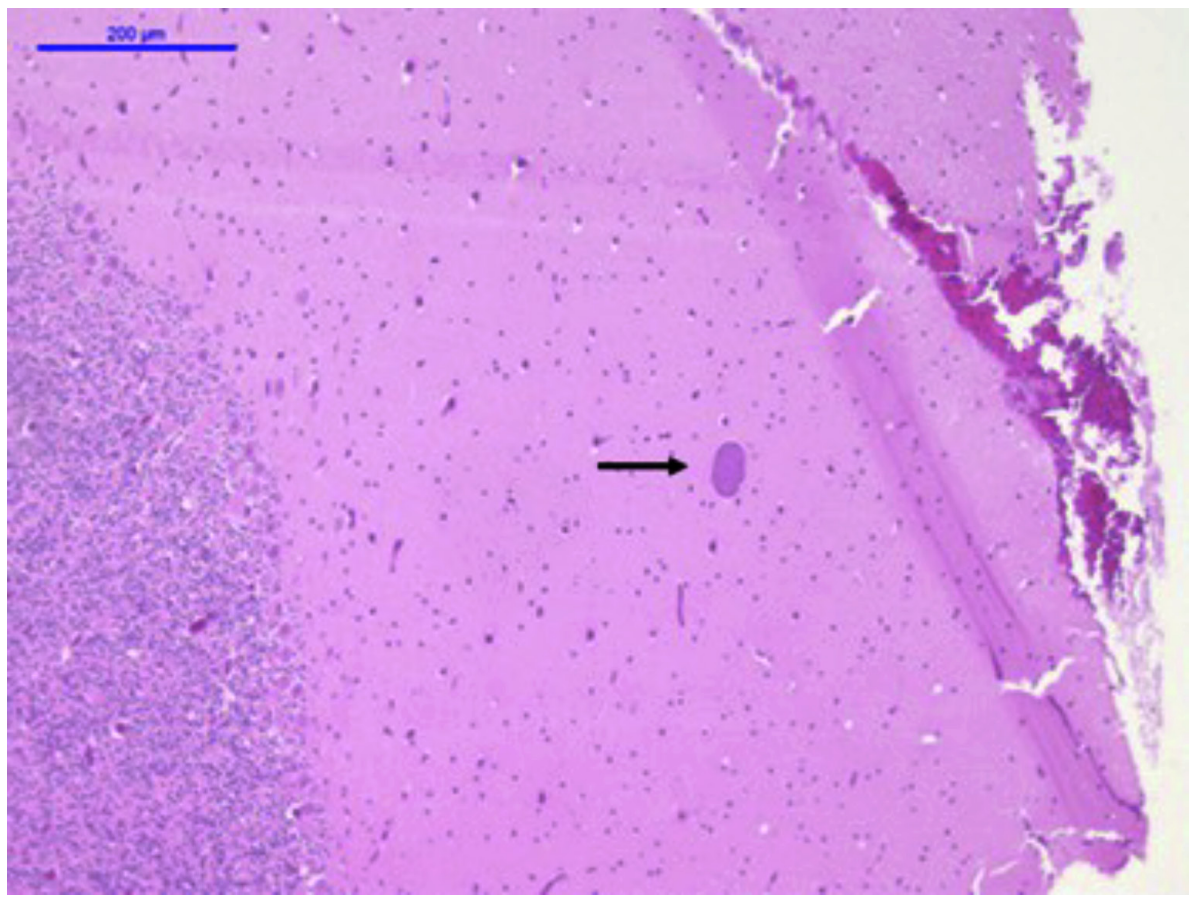

Figura 4. Vacuola parasitófora asociada a Sarcocystis sp. en corte histológico de cerebelo de Melanerpes formicivorus.

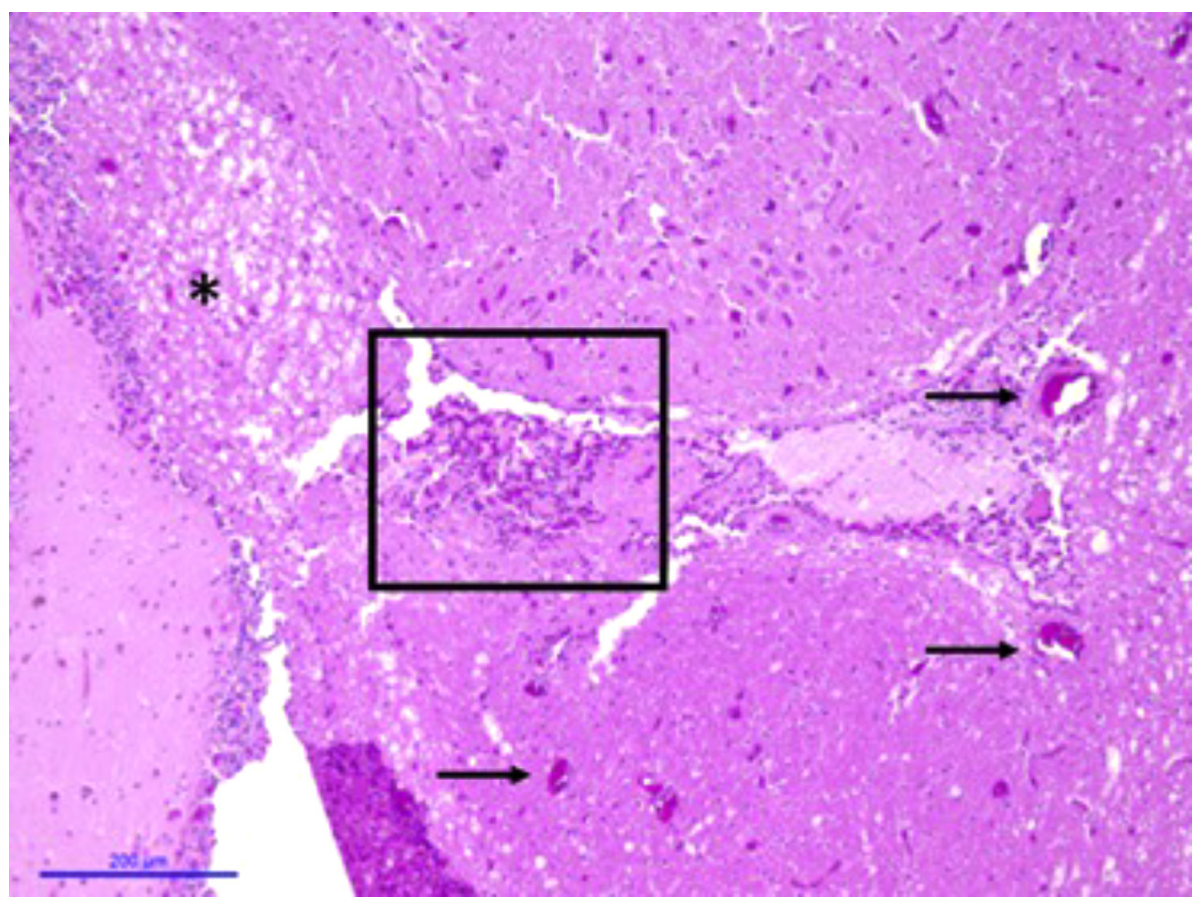

Figura 5. Histología de encéfalo en Melanerpes formicivorus, hay infiltrado perivascular de linfocitos (flechas), focos de espongiosis $(*)$ y de hemorragias (recuadro). 


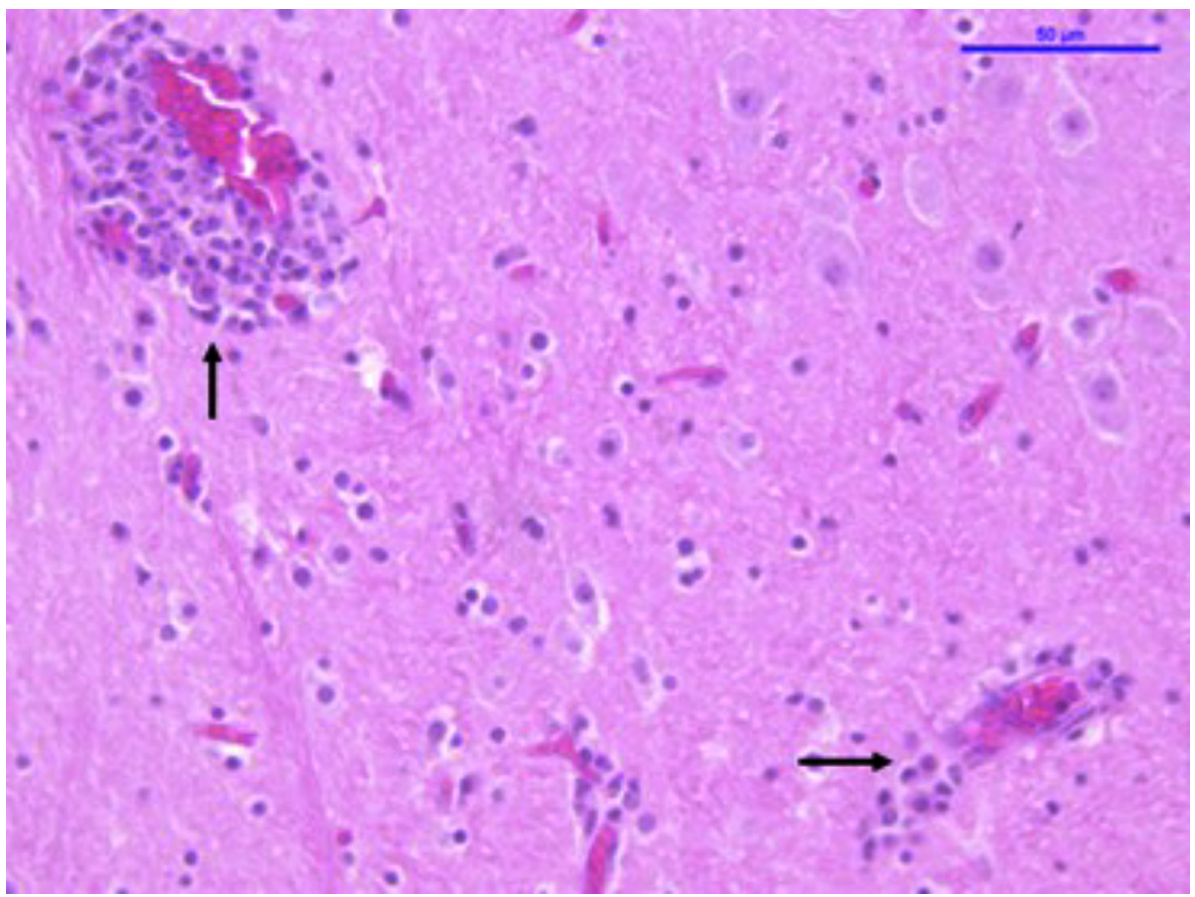

Figura 6. Histología de encéfalo en Melanerpes formicivorus. Infiltrado perivascular de linfocitos en encéfalo (flechas).

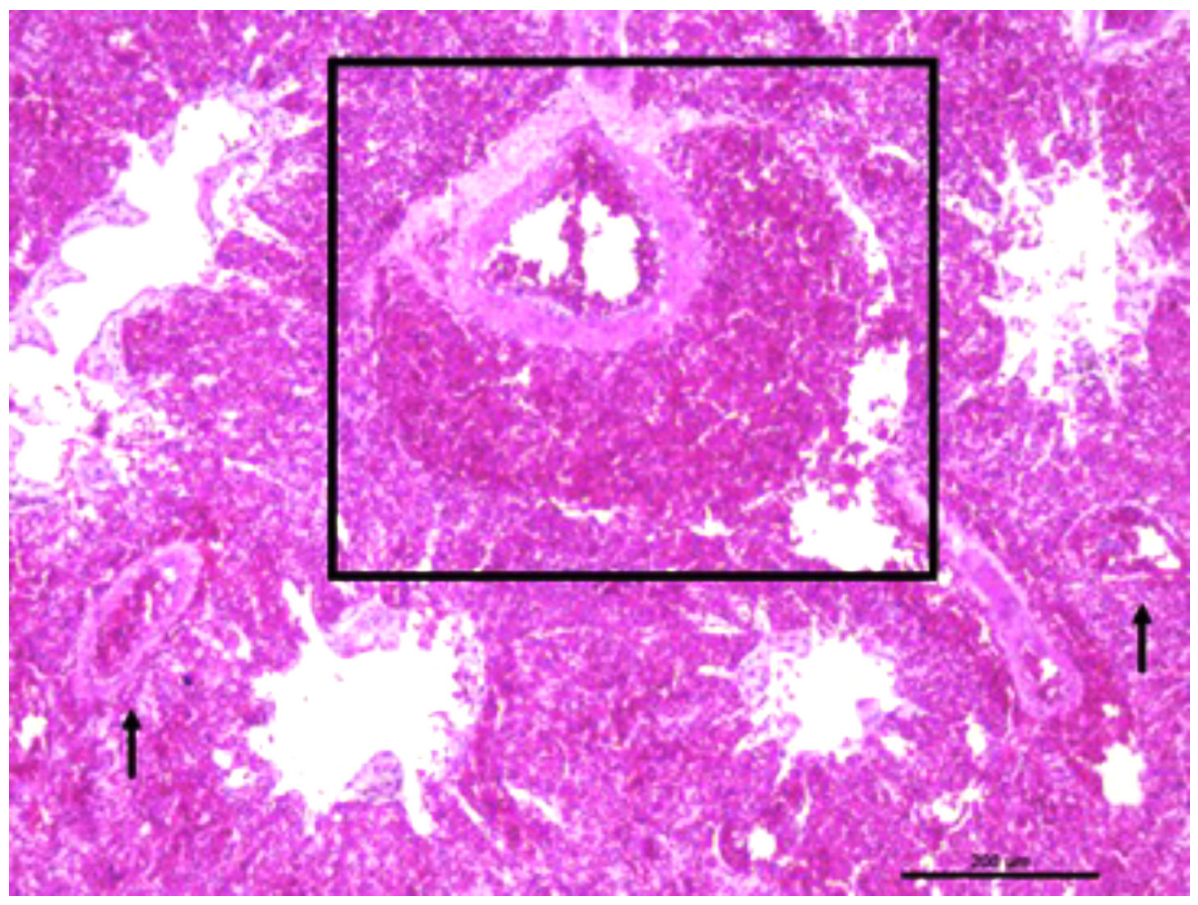

Figura 7. Histología de pulmón en Melanerpes formicivorus. Zonas de hemorragia (recuadro) y congestión de vasos sanguíneos en pulmón (flechas). 


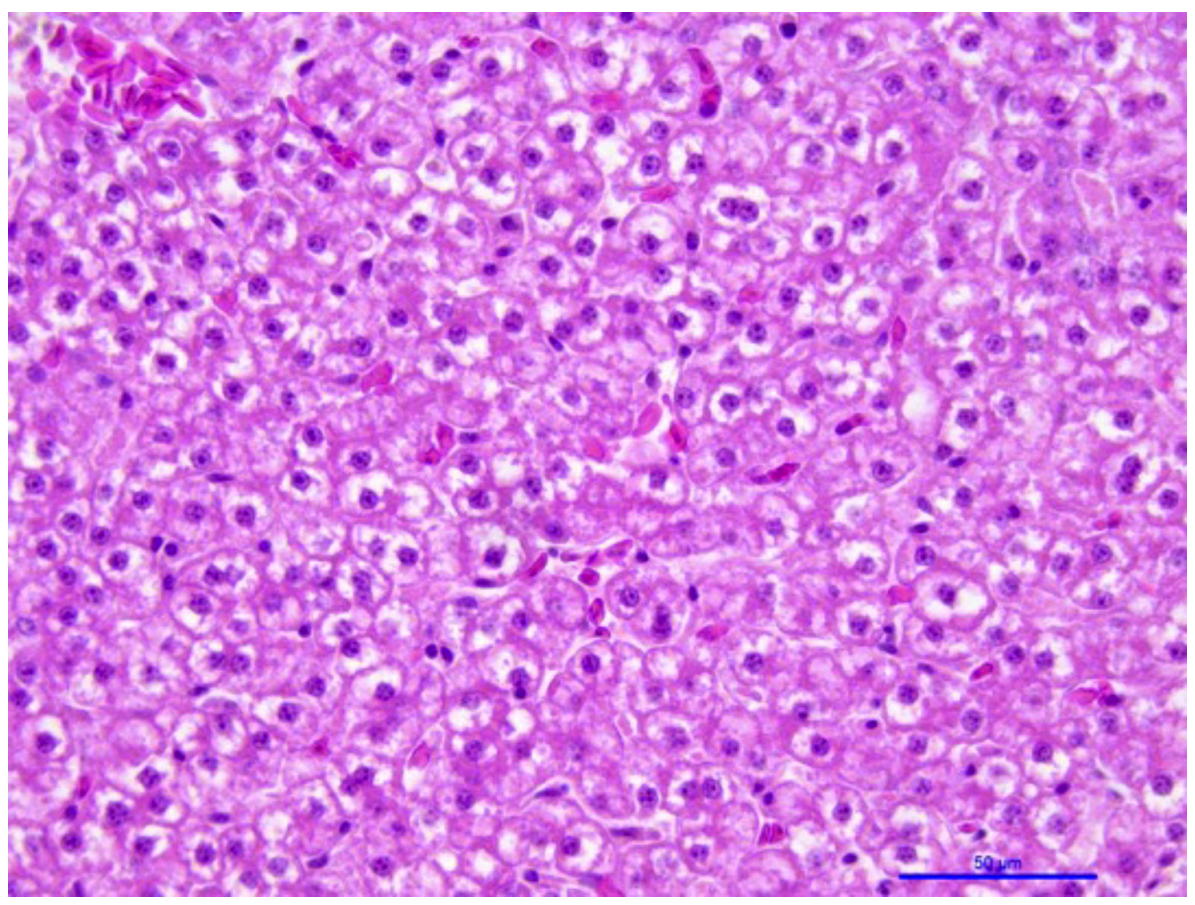

Figura 8. Microscopía del hígado, se observa degeneración grasa severa de los hepatocitos con distribución difusa en Melanerpes formicivorus.

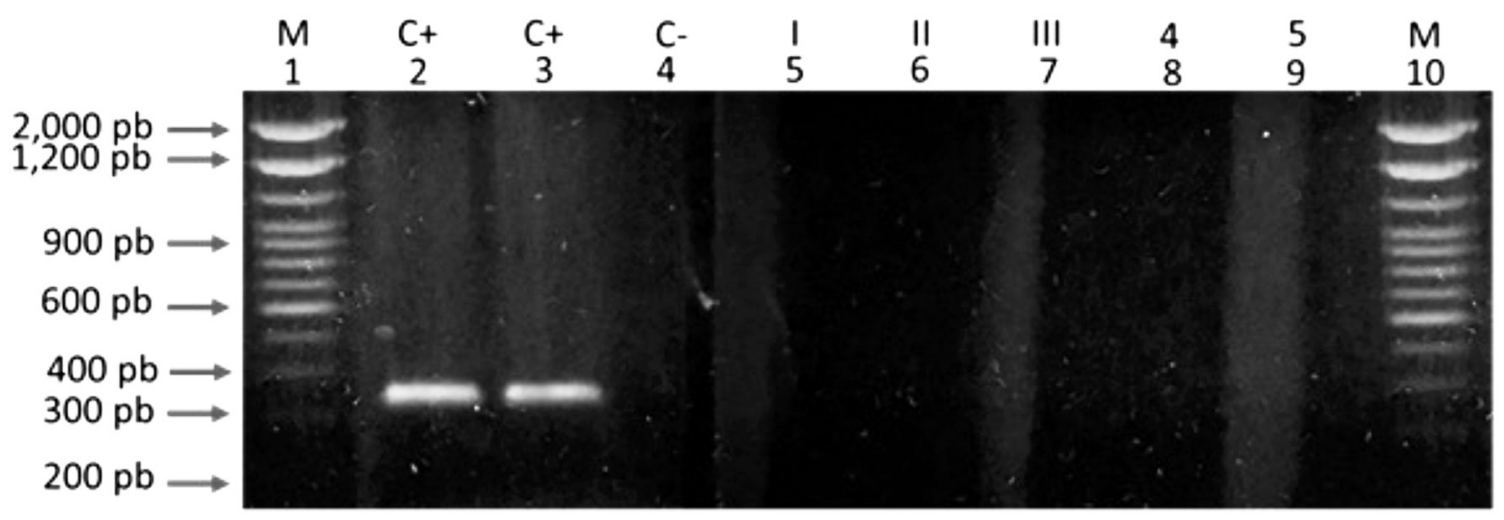

Figura 9. PCR Sarcocystis falcatula y S. neurona: gel de agarosa al 1 \% teñido con SYBR Safe. Carriles 1 y 10, marcador de peso molecular. Carriles 2 y 3, testigos positivos. Carril 4, testigo negativo. Carriles 5 a 7, tejido encefálico y de cerebelo con Sarcocystis. Carril 8, muestras de macerados de pulmón, hígado y encéfalo Carril 9, macerados de corazón, tráquea y músculo occipital. La banda en los carriles de los testigos positivos es del tamaño esperado. 


\section{Cuestionario diagnóstico}

1 ¿Cuál es tu diagnóstico de los principales hallazgos de la necropsia e histopatología?

2 ¿Cuál es la interpretación para los resultados de la imagen de gel de agarosa (Figura 9)? 


\section{? 1. ¿Cuál es tu diagnóstico de los principales hallazgos de la necropsia e histopatología?}

Respuesta: traumatismo torácico abierto en pájaro carpintero bellotero (Melanerpes formicivrus), asociado a hematomas en la articulación humero-clavicular y sobre los músculos intercostales superficiales de las costillas cinco a siete del lado derecho con un coágulo en la superficie del pulmón derecho. Además de un desgarre muscular y una fractura transversal media en la costilla seis también del lado derecho, asociada al traumatismo. Se hallaron estructuras blancas, alargadas y ovoides compatibles con sarcoquistes de Sarcocystis sp., con cambios histológicos asociados con rabdomiólisis y degeneración de fibras musculares.

En los cortes histopatológicos, un pulmón tenía una congestión difusa severa con zonas extensas de hemorragia.

Encefalomielitis y encefalomalacia linfocitaria asociada a sarcoquistes de Sarcocistys sp., donde se observó encefalitis multifocal aguda moderada, vasculitis e infiltrados perivasculares de linfocitos (Figura 10), focos de espongiosis en encéfalo y cerebelo (Figura 11). También había un sarcoquiste en el tejido encefálico (Figura 12).

\section{2. ¿Cuál es la interpretación para los resultados de la imagen de gel de agarosa ( Figura 9)?}

Respuesta: la Figura 9 indica que las muestras de los órganos no eran positivas a la prueba de PCR para detectar Sarcocystis neurona y S. falcatula; los resultados no coincidieron con los tejidos analizados, por lo que es posible que fuese otra especie del género Sarcocystis. Una mutación en la región del oligonucleótido o la presencia de ADN fragmentado de las muestras por el proceso de fijación y desparafinación no fueron muestras adecuadas para la prueba molecular. 


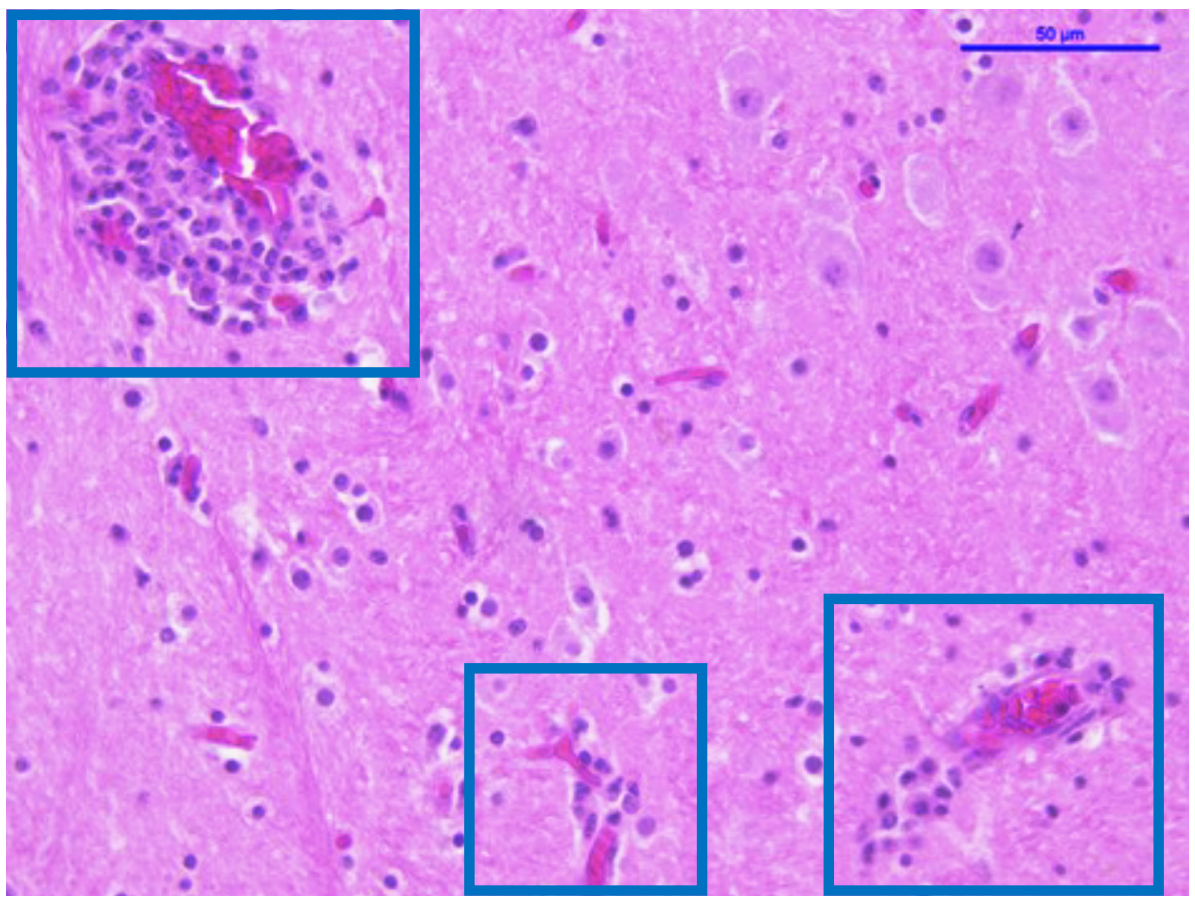

Figura 10. Histología del encéfalo de Melanerpes formicivorus, se observa el infiltrado perivascular de linfocitos en el encéfalo (recuadros).

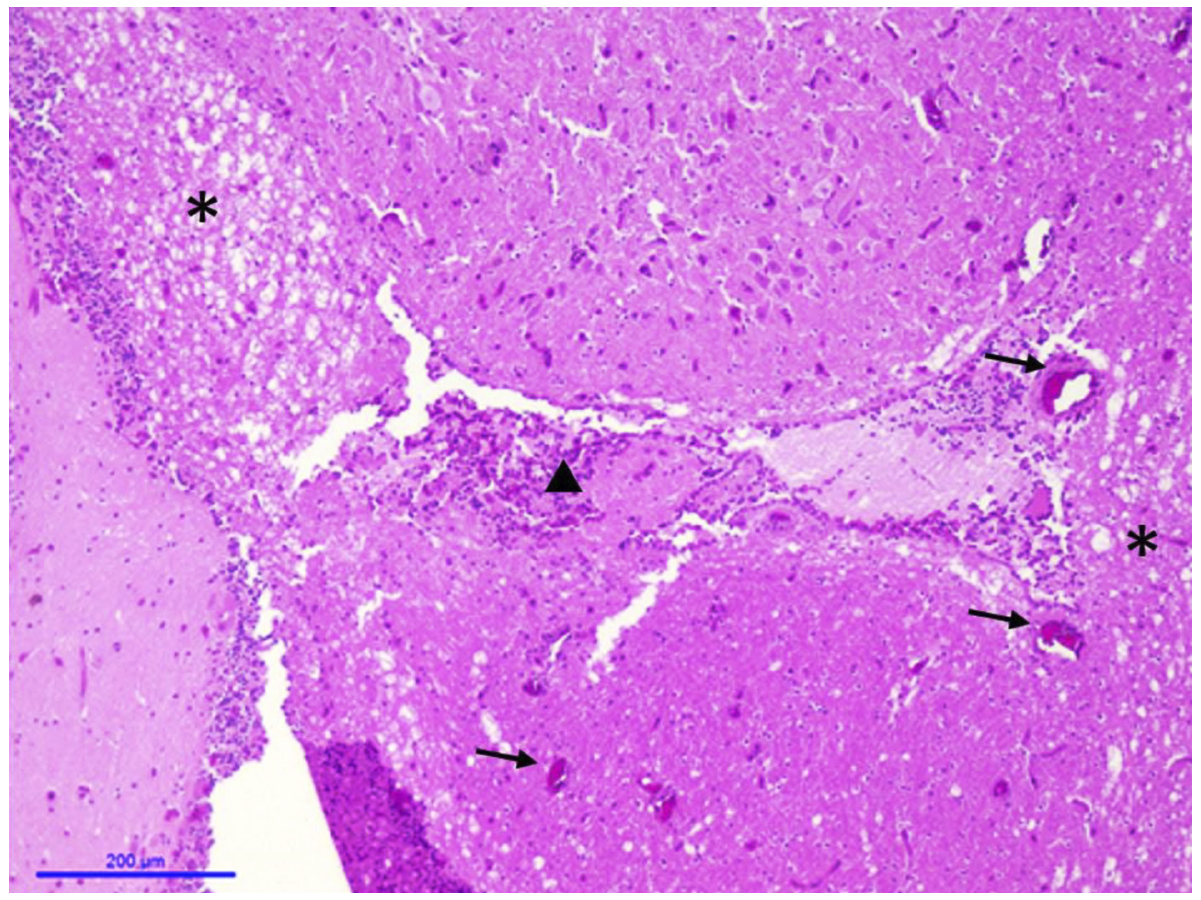

Figura 11. Histología del encéfalo de Melanerpes formicivorus, donde se observan focos de espongiosis $(*)$ y de hemorragias $(\mathbf{\Lambda})$; además, infiltrado linfocitario perivascular (flechas). 


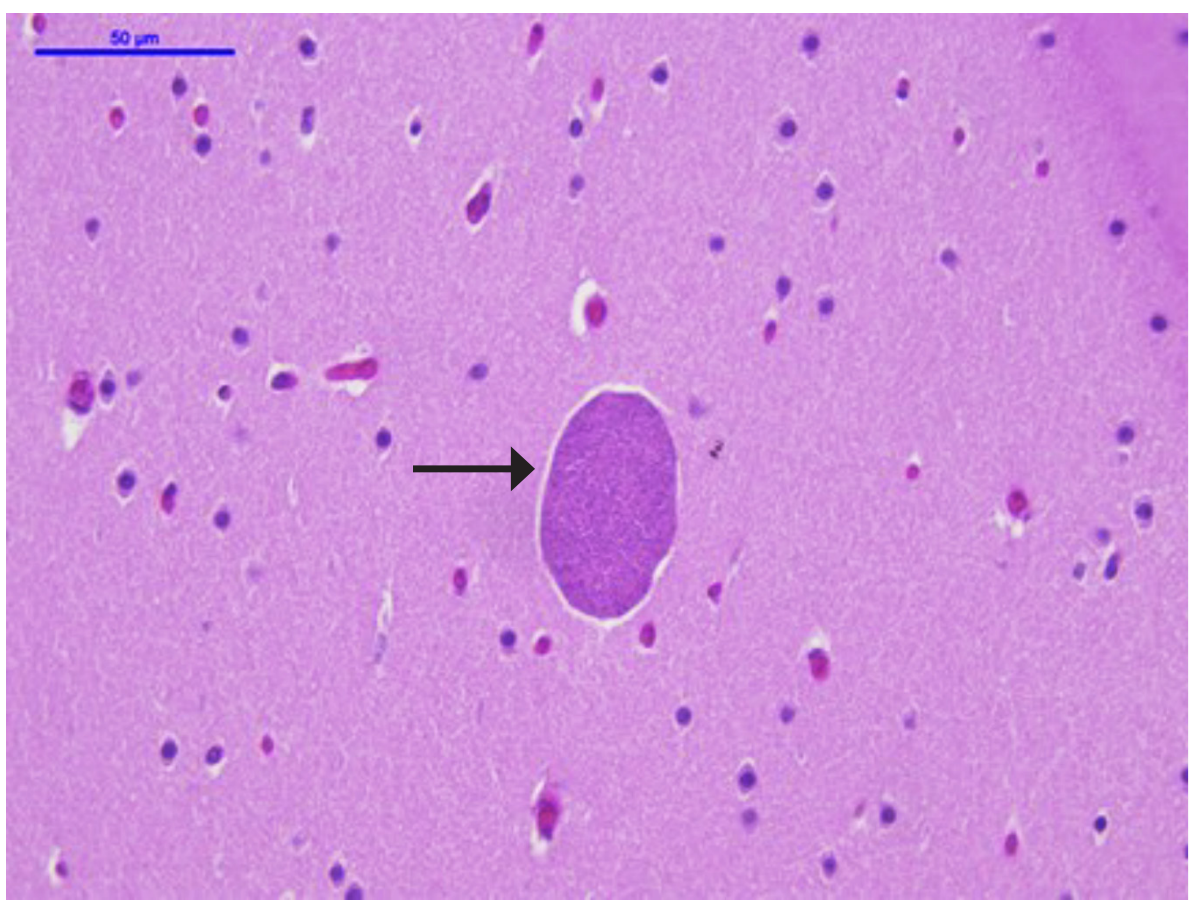

Figura 12. Histología de un sarcoquiste de Sarcocystis sp. en un corte de cerebelo de Melanerpes formicivorus (flecha). 


\section{Discusión y relevancia clínica}

Los hallazgos macroscópicos en los estudios post mortem sugirieron que la muerte del ave se debió a un traumatismo torácico abierto causado por las fracturas y hemorragias. El hallazgo incidental fue la presencia de quistes en músculos esqueléticos y las lesiones microscópicas en el encéfalo, asociadas con protozoarios del género Sarcocystis. Este caso evidencia por primera vez una encefalitis asociada a sarcoquistes de Sarcocystis sp. en un pájaro carpintero de vida libre en la Ciudad de México. Debido a que las aves como los pájaros carpinteros pueden ser huéspedes intermediarios para el Sarcocystis sp.

La mayoría de las veces el diagnóstico de una infección aguda por Sarcocystis suele ser post mortem o como un hallazgo incidental, debido a que no hay signos clínicos específicos o lesiones asociadas con esta infección ${ }^{2}$. En algunas aves como pollos de engorda se ha reportado debilidad muscular y signos nerviosos inespecíficos ${ }^{2}$.

En un búho cornudo (Bubo virginianus) se informa una posición anormal lateralizada a la izquierda en el cuello sin relación con un origen etiológico, más que con una encefalomalacia asociada con S. falcatula ${ }^{4}$. En otro caso, un ibis de cara roja (Phimosus infuscatus) asociado con S. falcatula tenía parálisis de las alas e incoordinación moderada que posteriormente se relacionó con meningoencefalitis necrotizante en el encéfalo y el cerebelo asociadas con sarcoquistes ${ }^{5}$.

Las especies del género Sarcocystis pertenecen al filo Apicomplexa, con un ciclo de vida con dos tipos de huéspedes: herbívoros u omnívoros como huéspedes intermediarios y carnívoros como huéspedes definitivos. El huésped definitivo consume la carne cruda del huésped intermediario infectada con los sarcoquistes del parásito, es entonces que los bradizoitos se liberan y la gametogonia o fase sexual se reproduce en el interior de los huéspedes definitivos, y de los gametos sexuales se produce el ooquiste que es evacuado en las heces, posteriormente un herbívoro susceptible se infecta al consumir alimento contaminado con heces portadoras de los ooquistes esporulados, una vez en el tracto gastrointestinal y por efecto de la tripsina y la bilis, se liberan a la luz intestinal los esporozoitos móviles que invadirán las células endoteliales de arterias de los linfonodos mesentéricos ${ }^{2,6}$.

En este caso, al estar en un área urbana muy amplia, los posibles depredadores y huéspedes definitivos más abundantes que pudieran tener los pájaros carpinteros son los perros y gatos, ya que son los animales más abundantes en zonas urbanas, existen otras especies de animales con acceso a ambientes abiertos, y que tienen la capacidad de contaminar con sus heces los sitos de alimentación de los pájaros carpinteros, como lo son mapaches, cernícalos, halcones y otros roedores. Después de que las fases 1 y 2 de esquizogonía se llevan a cabo en los linfonodos y en varios de los órganos del huésped intermediario, se liberan los merozoitos en el torrente sanguíneo, los cuales invaden arteriolas, capilares y venas, así se distribuye la infección a todo el cuerpo.

Algunas especies de Sarcocystis tienen la capacidad de infectar no sólo músculo esquelético, también tejido conectivo, células neurales y otros órganos; ya en el último ciclo de la esquizogonia los merozoitos invaden el tejido muscular y forman un sarcoquiste, donde en el interior el merozoito se diferencia en un metrocito que, a su vez, se diferencia por endodiogenia al interior de la vacuola 
parasitófora, la mayoría de estas estructuras se localizan entre las fibras musculares del musculo esquelético estriado. ${ }^{2,6}$.

Lo que los autores hasta hoy sabemos, es que no hay estudios sobre la presencia y prevalencia de Sarcocystis sp en perros u otra especie de fauna silvestre en la Ciudad de México, la investigación al respecto podría ayudar a conocer el impacto en la salud y conservación de las aves silvestres que la habita.

La prueba de PCR para detectar Sarcocystis neurona y S. falcatula fueron negativas en los tejidos analizados, por lo que es posible que fuese otra especie de género Sarcocystis, una mutación en la región del oligonucleótido o la presencia de ADN fragmentado de las muestras por el proceso de fijación y desparafinación.

Se han descrito más de doscientas especies de Sarcocystis en aves y mamíferos en el mundo. En México se han reportado distintos casos de Sarcocystis en aves; al norte del país ${ }^{7}$, de 2007 a 2008, en algunas especies de aves (Dendrocygna autumnalis, Aythya affinis, Anas carolinensis, Mareca americana, Anas acuta, Spatula cyanoptera) se reportó una prevalencia del $11 \%$ de Sarcocystis.

En 2014 se informó sobre diferentes casos de sarcoquistes en músculos esqueléticos en zanates (Quiscalus mexicanus), tordos (Molothrus aeneus) y gorriones (Aimophila ruficauda) ${ }^{8}$ y, en 2016, en sólo una de seis especies de patos (Spatula clypeata) $)^{7}$. Se ha descrito varias especies de Sarcocystis en aves y se han estudiado casos donde se encontró Sarcocystis horvathi en pollos (Gallus gallus), como huéspedes intermediarios y, en perros (Canis lupus), como huéspedes definitivos; mientras S. wenzeli también infecta a los pollos en la primera fase de su ciclo, pero infecta al gato (Felis cati) como huésped definitivo 6,9.

En anátidos se ha identificado Sarcocystis rileyi ${ }^{10}$. S. neurona ha sido huésped intermediario de los tordos cabeza café (Moluthrus ater) ${ }^{11}$. El águila real (Aquila chrysaetos) ${ }^{12}$, el urogallo (Tetrao urogallus $)^{13}$ y diferentes especies aviares se han caracterizado varias veces con Sarcocystis falcatula ${ }^{14}$.

El panorama de la Ciudad de México respecto a la diversidad de parásitos en parques a partir de heces de perros muestra que el $75.3 \%$ de los parques están contaminados, y Sarcocystis sp. es una de las especies parasitarias encontradas ${ }^{15}$., en este caso clínico, decidimos corroborar si el sarcoquiste hallado en el cadáver del pájaro carpintero estaba relacionado con las especies con más y diversos hospederos asentados en la literatura como son S. falcatula y S. neurona.

Al tener especies tanto domésticas, como ferales y silvestres (perros, gatos, ratones, ratas, tlacuaches, ardillas, cacomixtles y otras aves) que habitan las mismas áreas urbanas, se promueve que los parásitos tengan gran variedad de hospedadores y reservorios para Sarcocystis. Además de los perros, en otros animales se han identificado otras especies de Sarcocystis, como en tlacuaches (Didelphis sp.), casos reportados en Texas, EEUU y México ${ }^{16}$. En ratones y ardillas también se han detectado diversas especies de Sarcocystis, reservorio de huéspedes definitivos como gatos, serpientes y búhos ${ }^{17,18}$. También se han descrito títulos de anticuerpos contra $S$. neurona en más de siete especies de rapaces ${ }^{19}$.

En la mayoría de los casos, las lesiones macroscópicas se observan en músculos esqueléticos pectorales o alrededor de los miembros de las aves, no así, en los órganos internos. Esto es muy similar a este caso de estudio, en el que las lesiones en los músculos occipitales eran perceptibles, sin embargo, fue hasta la observación microscópica del encéfalo que se encontró la vacuola parasitófora asociada 
con infiltrados linfocitarios perivasculares y en la neurópila, degeneración vacuolar, hemorragias en el encéfalo y el cerebelo.

Los hallazgos histopatológicos en este reporte clínico son similares a las lesiones encontradas en distintas especies de aves, donde la historia clínica y los datos de la inspección física no podían asociarse con agentes etiológicos más comunes, hasta los estudios post mortem, donde se asocia la encefalitis con infecciones por Sarcocystis sp. Por lo que se sugiere que, cuando las aves cursen con signos nerviosos como parálisis de miembros, posiciones anormales del cuello, entre otros, y con una evolución clínica aguda o crónica y sin evidencia de traumatismo, el diagnóstico diferencial se posibilite con infección por Sarcocystis. Algunas lesiones histológicas recabadas de la literatura, se describen en el Cuadro 1 y a veces se han asociado a signos clínicos nerviosos inespecíficos. 
Cuadro 1. Lesiones histológicas descritas por varios autores.

\begin{tabular}{|c|c|c|c|}
\hline Ave (especie) & Hallazgos microscópicos en encéfalo & Signos clínicos & \\
\hline $\begin{array}{l}\text { Paloma dómestica } \\
\text { Columba livia }\end{array}$ & $\begin{array}{l}\text { I Encefalitis granulomatosa necrotizante multifocal } \\
\text { coalescente. } \\
\text { I Infiltrados perivasculares. } \\
\text { I Proliferación de células gliales. } \\
\text { I Encefalomalacia del tronco encefálico y el cerebelo. } \\
\text { I Presencia de esquizontes en el neurópilo. }\end{array}$ & $\begin{array}{l}\text { Apatía, debilidad } \\
\text { generalizada, torticolis } \\
\text { y opistótonos, tremores } \\
\text { musculares, parálisis y } \\
\text { tremores. }\end{array}$ & $\begin{array}{l}\text { Olias et al., } \\
2009^{6}\end{array}$ \\
\hline $\begin{array}{l}\text { Aguila real } \\
\text { Aquila chrysaetos }\end{array}$ & $\begin{array}{l}\text { I Meningoencefalitis, necrosis del neurópilo, vasculitis } \\
\text { e infiltrados de mononucleares. } \\
\text { I Esquizontes en la periferia de los vasos sanguíneos. }\end{array}$ & $\begin{array}{l}\text { Leve torticolis, depresión, } \\
\text { ceguera y buena condición } \\
\text { corporal. }\end{array}$ & $\begin{array}{l}\text { Dubey et al., } \\
1991^{12}\end{array}$ \\
\hline $\begin{array}{l}\text { Urogallo común } \\
\text { Tetrao urogallus }\end{array}$ & $\begin{array}{l}\text { I Presencia de nódulos de células gliales. } \\
\text { I Infiltrados perivasculares de linfocitos. }\end{array}$ & $\begin{array}{l}\text { Un cadáver sin reporte de } \\
\text { signos clínicos. }\end{array}$ & $\begin{array}{l}\text { Dubey et al., } \\
1998^{13}\end{array}$ \\
\hline $\begin{array}{l}\text { Azor común } \\
\text { Accipiter gentilis } \\
\text { atricapillus }\end{array}$ & $\begin{array}{l}\text { I Encefalomalacia y necrosis en el tronco encefálico. } \\
\text { I Encefalitis linfocitaria y numerosas células } \\
\text { plasmáticas, y macrófagos asociados a } \\
\text { esquizontes. }\end{array}$ & $\begin{array}{l}\text { Ave deprimida, inactiva } \\
\text { y con anorexia, } \\
\text { semiextensión del ala } \\
\text { derecha y propiocepción } \\
\text { disminuida del lado } \\
\text { derecho del cuerpo. }\end{array}$ & $\begin{array}{l}\text { Aguilar et al., } \\
1991^{20}\end{array}$ \\
\hline $\begin{array}{l}\text { Varios psitácidos del } \\
\text { "Zoológico de San } \\
\text { Diego", EEUU }\end{array}$ & $\begin{array}{l}\text { I Sarcoquistes de los protozoarios asociados a } \\
\text { necrosis del encéfalo. }\end{array}$ & $\begin{array}{l}\text { Muerte sin signos previos, } \\
\text { anorexia, debilidad, ataxia, } \\
\text { paresia posterior, torticolis } \\
\text { y tremores de la cabeza, } \\
\text { muerte aguda. }\end{array}$ & $\begin{array}{l}\text { Hillyer et al., } \\
1991^{21}\end{array}$ \\
\hline $\begin{array}{l}\text { Gallo dómestico } \\
\text { Gallus gallus }\end{array}$ & $\begin{array}{l}\text { I Encefalitis necrotizante con proliferación de } \\
\text { mononucleares, heterófilos y células gigantes } \\
\text { multinucleadas. } \\
\text { I Esquizontes y merozoitos en las lesiones. }\end{array}$ & $\begin{array}{l}\text { Incoordinación que fue } \\
\text { empeorando, letargia y } \\
\text { plumas erizadas, torticolis y } \\
\text { opistótonos. }\end{array}$ & $\begin{array}{l}\text { Mutalib et al., } \\
1995^{22}\end{array}$ \\
\hline $\begin{array}{l}\text { Pavo } \\
\text { Meleagris gallopavo }\end{array}$ & $\begin{array}{l}\text { I Esquizontes y merozoitos asociados con áreas de } \\
\text { inflamación y necrosis. } \\
\text { I Encefalitis necrótica con gliosis, e infiltrados } \\
\text { perivasculares linfocitarios. }\end{array}$ & $\begin{array}{l}\text { Ataxia y emaciación de } \\
\text { aves adultas. }\end{array}$ & $\begin{array}{l}\text { Teglas et al., } \\
1998^{23}\end{array}$ \\
\hline $\begin{array}{l}\text { Aguila calva } \\
\text { Haliaeetus } \\
\text { leucocephalus }\end{array}$ & $\begin{array}{l}\text { I Moderada meningoencefalomielitis linfoplasmática } \\
\text { e histiocítica en el encéfalo y el cerebelo. } \\
\text { I Numerosos infiltrados perivasculares. } \\
\text { I Pérdida del segmento granular y de las células } \\
\text { de Purkinje, vacuolización y atrofia de la capa } \\
\text { molecular en las folias del cerebelo. } \\
\text { I Merozoitos y esquizontes en el parénquima } \\
\text { cerebelar. }\end{array}$ & $\begin{array}{l}\text { Incoordinación, desviación } \\
\text { a la izquierda, miembros } \\
\text { débiles, tremores y pérdida } \\
\text { de la visión. }\end{array}$ & $\begin{array}{l}\text { Olson et al., } \\
2007^{24}\end{array}$ \\
\hline
\end{tabular}




\section{Financiamiento}

El financiamiento de la consulta, la necropsia y el estudio histopatológico remitido al Laboratorio del Diagnóstico e Investigación en Enfermedades de las Aves del Departamento de Medicina y Zootecnia de Aves fue cubierto por los propietarios del ave. La extracción y estudios de PCR fueron cubiertos por el Hospital de Aves de Ornato, Compañía y Silvestres del mismo Departamento académico.

\section{Agradecimientos}

Gracias por el apoyo del personal médico y académico del Hospital de Aves de Ornato, compañía y silvestres de la FMVZ.

Agradecemos al personal del Laboratorio de diagnóstico en enfermedades de las Aves por sus atenciones..

\section{Conflictos de interés}

Los autores declaran que no hay conflictos de interés para la publicación de esta investigación..

\section{Contribución de los autores}

EPJR fue el encargado de la necropsia, recopiló el archivo, escribió el manuscrito e hizo la revisión bibliográfica.

NLCA fue el patólogo responsable del diagnóstico, el trabajo fotográfico y la revisión del manuscrito.

GGE fue el responsable de la caracterización molecular de las muestras y la revisión del manuscrito.

FCM fue el responsable de la caracterización molecular de las muestras.

\section{Referencias}

1. Majó N, Dolz R. Atlas de la necropsia aviar. Diagnóstico macroscópico. Toma de muestras. Barcelona, España: SERVET; 2011.

2. Florin-Christensen $M$, Schnittger $L$, editores. Parasitic Protozoa of Farm Animals and Pets. Switzerland: Springer, Cham; 2018.

3. Tanhauser SM, Yowell CA, Cutler TJ, Greiner EC, MacKay RJ, Dame JB. Multiple DNA Markers Differentiate Sarcocystis neurona and Sarcocystis falcatula. The Journal of Parasitology [Internet]. 1999;85(2):221-8. Disponible en: http:// www.jstor.org/stable/3285623 Doi: 10.2307/3285623

4. Wünschmann A, Rejmanek D, Cruz-Martinez L, Barr BC. Sarcocystis falcatulaAssociated Encephalitis in a Free-Ranging Great Horned Owl (Bubo Virginianus). J VET Diagn Invest 2009;21(2):283-7. Doi: 10.1177/104063870902100223

5. Konradt G, Bianchi MV, Leite-Filho RV, da Silva BZ, Soares RM, Pavarini SP, Driemeier D. Necrotizing meningoencephalitis caused by Sarcocystis falcatula in barefaced ibis (Phimosus infuscatus). Parasitology Research. 2017;1 16(2):809-12. Doi: 10.1007/s00436-016-5341-6

6. Olias P, Gruber AD, Heydorn AO, Kohls A, Mehlhorn H, Hafez HM, Lierz M. A novel Sarcocystis-associated encephalitis and myositis in racing pigeons. Avian Pathology. abril de 2009;38(2):121-8. Doi: 10.1080/03079450902737847

7. Padilla-Aguilar P, Romero-Callejas E, Osorio-Sarabia D, Ramírez-Lezama J, Cigarroa-Toledo N, Machain-Williams C, Manterola C, Zarza H. Detection and Mo- 
lecular Identification of Sarcocystis rileyi (Apicomplexa: Sarcocystidae) From a Northern Shoveler (Anas clypeata) in Mexico. Journal of Wildlife Diseases. 2016;52(4):931-5. Doi: 10.7589/2016-01-004

8. Sánchez-Godoy F, Chávez-Maya F, Méndez-Bernal A, García-Espinosa G, Guerrero-Molina C, Ledesma-Martínez N, Morales-Salinas E. Sarcocystis sp. parasites in the Mexican Great-tailed Grackle (Quiscalus mexicanus), Bronzed Cowbird (Molothrus aeneus), and Stripe-headed Sparrow (Aimophila ruficauda). Vet Mex OA. 2014;1(2). Doi: 10.21753/vmoa.1.2.336.

9. Odening, K. The present state of species-systematics in Sarcocystis lankester, (1882). (Protista, Sporozoa, Coccidia). Systematic Parasitology, 1998;3(41):209-233. Doi :10.1023/A:1006090232343.

10. Cawthorn, R. J., Rainnie, D., \& Wobeser, G. Experimental transmission of Sarcocystis sp. (Protozoa: Sarcocystidae) between the shoveler (Anas clypeata) duck and the striped skunk (Mephitis mephitis). Journal of Wildlife Diseases, 1981;17(3):389-394. Doi :10.7589/0090-3558-17.3.389.

11. Mansfield LS, Mehler S, Nelson K, Elsheikha HM, Murphy AJ, Knust B, Tanhauser SM, Gearhart PM, Rossano MG, Bowman DD, Schott HC, Patterson. Brown-headed cowbirds (Molothrus ater) harbor Sarcocystis neurona and act as intermediate hosts. Veterinary Parasitology [Internet]. 2008;153(1):24-43. Disponible en: https://www.sciencedirect.com/science/article/pii/S0304401707006589. Doi: 10.1016/j.vetpar.2007.12.016

12. Dubey, J. P., Porter, S. L., Hattel, A. L., Kradel, D. C., Topper, M. J., Johnson, L., \& Porter, S. L. Sarcocystosis-associated clinical encephalitis in a golden eagle (Aquila chrysaetos). Journal of Zoo and Wildlife Medicine. 1991:22(2);233236 Disponible en: https://www.jstor.org/stable/20095145

13. Dubey, J. P., Rudbäck, E., \& Topper, M. J. Sarcocystosis in capercaillie (Tetrao urogallus) in Finland: description of the parasite and lesions. The Journal of parasitology. 1998:84(1):104-108. Doi: 10.2307/3284538.

14. Box, E. D., Meier, J. L., \& Smith, J. H. Description of Sarcocystis falcatula, Stiles, 1893, a parasite of birds and opossums. The Journal of protozoology. 1984;31(4):521. Doi: 10.1111/j.1550-7408.1984.tb05495.x.

15. Lara Reyes E, Figueroa Ochoa JM, Quijano Hernández IA, Del Ángel Caraza J, Victoria Mora JM, Barbosa Mireles MA, Beltrán León T. Frecuencia de parásitos gastrointestinales de perros en parques públicos de dos municipios vecinos del Estado de México. NOVA [Internet]. 2019;17(32). Disponible en: https://revistas.unicolmayor.edu.co/index.php/nova/article/view/1033. Doi: 10.25058/24629448.3634

16. Modarelli, J. J., Westrich, B. J., Milholland, M., Tietjen, M., Castro-Arellano, I., Medina, R. F., \& Esteve-Gasent, M. D. Prevalence of protozoan parasites in small and medium mammals in Texas, USA.International Journal for Parasitology: Parasites and Wildlife. 2020.11:229-234. Doi: https://doi.org/10.1016/j. ijppaw.2020.02.005

17. Fernández-Escobar, M., Millán, J., Chirife, A. D., Ortega-Mora, L. M., \& Calero-Bernal, R. Molecular survey for cyst-forming coccidia (Toxoplasma gondii, Neospora caninum, Sarcocystis spp.) in Mediterranean periurban micromammals. Parasitology Research. 2020;119(8):2679-268. Doi: 10.1007/s00436-020-06777-2 
18. Seksenova D, Esimov B, Ibragimova Z. Sarcocystis in some rodents and birds. News of the National Academy of Sciences of the Republic of Kazakhstan. 2020;2(338):56-61. Doi: 10.32014/2020.2519-1629.13

19. Sato, A. P., de Aquino Goulart, M., Konell, A. L., de Oliveira Koch, M., da Fonseca, F. M., Morel, A. P., \& Locatelli-Dittrich, R. Serosurvey of Toxoplasma gondii, Neospora caninum and Sarcocystis neurona in raptors and risk factor analysis. Parasitology International. 2021;82:102312. Doi: 10.1016/j.parint.2021.102312

20. Aguilar RF, Shaw DP, Dubey JP, Redig P. Sarcocystis-Associated Encephalitis in an Immature Northern Goshawk (Accipiter gentilis atricapillus). Journal of Zoo and Wildlife Medicine [Internet]. 1991;22(4):466-9. Disponible en: http://www. jstor.org/stable/20095190

21. Hillyer EV, Anderson MP, Greiner EC, Atkinson CT, Frenkel JK. An Outbreak of Sarcocystis in a Collection of Psittacines. Journal of Zoo and Wildlife Medicine [Internet]. 1991;22(4):434-45. Disponible en: http://www.jstor.org/ stable/20095186

22. Mutalib A, Keirs R, Maslin W, Topper M, Dubey JP. Sarcocystis-associated encephalitis in chickens. Avian Diseases. 1995;39(2):436-40. Doi: 10.2307/1591891.

23. Teglas M, Little S, Latimer K, Dubey J. Sarcocystis-associated encephalitis and myocarditis in a wild turkey (Meleagris gallopavo). J Parasitol [Internet]. 1998;84(3):661-3. Disponible en: http://europepmc.org/abstract/ MED/9645885. Doi: 10.2307/3284751.

24. Olson EJ, Wünschmann A, Dubey JP. Sarcocystis sp.-Associated Meningoencephalitis in a Bald Eagle (Haliaeetus Leucocephalus). J VET Diagn Invest [Internet]. 2007;19(5):564-8. Disponible en: https://doi. org/10.1177/104063870701900519 10.1177/104063870701900519. 


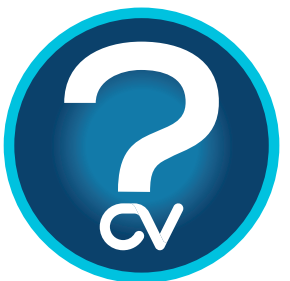

RETO DIAGNÓSTICO: Hallazgos incidentales en la necropsia de un pájaro carpintero bellotero (Melanerpes formicivorus)

\section{Resumen}

Descripción del caso. Se analizó el caso de un pájaro carpintero bellotero adulto de vida silvestre en la Ciudad de México que fue remitido al Laboratorio de Diagnóstico de Enfermedades de las Aves, en la Facultad de Medicina Veterinaria y Zootecnia-UNAM.

Hallazgos clínicos e interpretación. En el cadáver del ave se observaron lesiones post mortem asociadas con un traumatismo torácico, además de estructuras blancas alargadas en las fibras musculares en los músculos esqueléticos occipitales de aproximadamente $2 \times 1 \mathrm{~mm}$.

Las lesiones macroscópicas sugieren que la muerte se debió a un traumatismo torácico abierto, sin embargo, el ave cursaba con una encefalomielitis y encefalomalacia del cerebelo relacionada con una vacuola parasitófora asociada a parásitos del filo apicomplexa.

Tratamiento y evolución. Se desconoce si se administró tratamiento previo. Pruebas de laboratorio. A partir de las muestras para el estudio histopatológico, se observaron lesiones inflamatorias en el encéfalo y vacuolas parasitóforas compatibles con sarcoquistes tanto en el encéfalo como en los músculos occipitales. Se extrajo ADN y se realizó PCR para identificar y clasificar al parásito como Sarcocystis neurona o S. falcatula.

Palabras clave: encefalitis, vacuola parasitófora, encéfalomalacia, Sarcocystis, sarcoquiste, Melanerpes. 


\section{Incidental findings at necropsy of an acorn woodpecker (Melanerpes formicivorus)}

\section{Abstract}

Case report. An adult acorn woodpecker from wildlife in Mexico City that was referred to the Laboratory for Diagnosis of Bird Diseases, at the School of Veterinary Medicine and Zootechnics UNAM.

Clinical findings and interpretation. Postmortem lesions associated with chest trauma were observed in the bird carcass, in addition to elongated white structures into the muscle fibers in the occipital skeletal muscles of approximately $2 \times 1 \mathrm{~mm}$.

The macroscopic lesions suggest that the death was due to an open chest trauma; however, the bird presented subclinically encephalomyelitis and encephalomalacia of the cerebellum related to a parasitophorous vacuole associated with parasites of the apicomplexa phylum.

Treatment and evolution. It is unknown whether prior treatment was administered.

Lab tests. From the samples for the histopathology, inflammatory lesions were observed in the brain and parasitophorous vacuoles compatible with Sarcocysts, that where localized in both brain and the occipital muscles. DNA was extracted and PCR was performed to identify and classify the parasite as Sarcocystis neurona or S. falcatula.

Keywords: encephalitis, parasitophorous vacuole, encephalomalacia, Sarcocystis, sarcocyst, Melanerpes. 